\title{
Higher BMI Is Associated with Reduced Cognitive Performance in Division I Athletes
}

\author{
Andrew Fedor John Gunstad \\ Department of Psychology, Kent State University, Kent, OH, USA
}

\section{Key Words}

Body mass index $\cdot$ Physical activity $\cdot$ Risk factors $\cdot$ Weight status

\begin{abstract}
Objective: Poor cardiovascular fitness has been implicated as a possible mechanism for obesity-related cognitive decline, though no study has examined whether BMI is associated with poorer cognitive function in persons with excellent fitness levels. The current study examined the relationship between BMI and cognitive function by the Immediate Post Concussion and Cognitive Test (ImPACT) in Division I collegiate athletes. Methods: Participants had an average age of $20.14 \pm 1.78$ years, were $31.3 \%$ female, and $53.9 \%$ football players. BMI ranged from 19.04 to 41.14 and averaged $26.72 \pm 4.62$. Results: Regression analyses revealed that BMI incrementally predicted performance on visual memory $\left(R^{2}\right.$ change $\left.=0.015, p=0.026\right)$ beyond control variables. Follow-up partial correlation analyses revealed small but significant negative correlations between BMI and verbal memory $(r=-0.17)$, visual memory $(r=-0.16)$, and visual motor speed $(r=-0.12)$. Conclusions: These results suggest that higher BMI is associated with reduced cognitive function, even in a sample expected to have excellent levels of cardiovascular fitness. Further work is needed to better understand mechanisms for these associations.

Copyright (c) 2013 S. Karger GmbH, Freiburg
\end{abstract}

\section{Introduction}

Despite increased awareness, the prevalence of obesity continues to rise in many countries. In 2008, an estimated 1.5 billion people worldwide were overweight (BMI $\geq 25-29.9$ $\mathrm{kg} / \mathrm{m}^{2}$ ), with 500 million considered obese (BMI $\geq 30 \mathrm{~kg} / \mathrm{m}^{2}$ ) [1]. Overweight and obese indi- 
Fedor et al.: Higher BMI Is Associated with Reduced Cognitive Performance in Division I Athletes

viduals are at elevated risk for numerous health problems, including cardiovascular disease, type 2 diabetes, musculoskeletal disorders, and even some forms of cancer [1-3]. The cost of obesity and these comorbid conditions is substantial, totaling nearly USD 150 billion per year in the USA alone [4].

There is growing evidence that obesity is also associated with adverse neurocognitive outcomes including Alzheimer's disease [5], stroke, and vascular dementia [6]. Research also demonstrates an association between obesity and impaired cognitive functioning long prior to the onset of these conditions. Even after controlling for comorbid medical conditions, obese individuals exhibit deficits in multiple cognitive domains, including attention, executive function, and memory [7-16].

The mechanisms for obesity-related cognitive dysfunction remain poorly understood. Neuroimaging studies link obesity to structural and functional changes, including greater atrophy, development of white matter hyperintensities [5], reduced neural connectivity [17], and decreased blood flow in frontal brain regions [18]. Other work demonstrates aspects of glycemic controls, including altered insulin sensitivity and insulin resistance, as important contributors to obesity-related cognitive dysfunction [19-21].

Another likely contributor to obesity-related cognitive dysfunction is reduced cardiovascular fitness. Many obese individuals have poor cardiovascular fitness, perhaps attributable to low levels of physical activity found in this population [22,23]. In turn, low levels of cardiovascular fitness are associated with reduced cognitive function in a variety of healthy and patient samples $[24,25]$, and improvements in cardiovascular fitness correspond to improved neuropsychological test performance [17, 24, 26, 27]. Similarly, a weight loss program combining diet and exercise was associated with improved neurocognitive functioning in obese adults [28].

Despite these findings, the contribution of physical fitness to obesity-related cognitive function remains unclear as risk factors often comingle. For example, American football players often have cardiovascular risk factors and type 2 diabetes [29], despite excellent fitness levels. No study to date has examined the association between body composition and cognitive function in a sample of persons expected to have better than average fitness levels. To do so, we examined BMI and cognitive function in a sample of Division I collegiate athletes. Based on the independent effect of obesity on cognition in past work, we expected that higher BMI would be associated with poorer cognitive function.

\section{Participants and Methods}

\section{Participants}

Data were collected from 323 (222 males; 101 females) college student athletes at a midsized Midwestern public university. Participants ranged in age from 18 to 24 years (mean \pm SD $20.14 \pm 1.78$ years). Athletes were active in sports such as football, men's and women's basketball, gymnastics, field hockey, men's and women's track, cheerleading, wrestling, and women's soccer. Of note, the average number of concussions for the entire sample was $0.35 \pm 0.7$ ).

Non-Football Sample

Athletes who did not play football were grouped together for comparison against football players during data analysis. Participants in the non-football group ranged in age from 17 to 23 years (19.90 \pm 1.24 years). This group was composed of 48 males and 101 females. The number of athletes in each sport varied from a low of 4 (baseball) to a high of 21 (cheerleading). 
Fedor et al.: Higher BMI Is Associated with Reduced Cognitive Performance in Division I Athletes

\section{Measures}

Immediate Post Concussion Assessment and Cognitive Testing (ImPACT)

The ImPACT is a computerized neuropsychological test battery designed to assess attention, memory, and processing speed. After completion of the test, five composite scores as well as a total score are generated, including verbal memory, visual memory, visual motor speed, reaction time, and impulse control [30]. The ImPACT has high convergent validity [31] as well as excellent sensitivity and specificity [32] in college athlete populations.

BMI Calculation

BMI was calculated from self-report of height and weight collected during the demographic section of the ImPACT.

\section{Procedures}

Athletes completed testing in group format, though each was at an individual workstation and separated into differentrooms. Testing was administered by faculty and graduate students in the psychology department, while athletic training staff provided supervision.

\section{Data Analysis}

A series of regressions examined whether higher BMI was associated with reduced performance on composite scores of the ImPACT. Age, gender, sport, and number of past concussions were entered into Block 1 of the regression as control variables and BMI into Block 2 . Change in predictive ability ( $\mathrm{R}^{2}$ change) was examined to determine significance. To clarify these findings, partial correlations were also calculated between BMI and ImPACT composite scores separately for each gender and then within the subsample of football players. All data analyses were conducted on SPSS version 16 [33].

\section{Results}

\section{BMI Is Associated with ImPACT Test Performance}

Regressions were conducted between BMI and composite scores on the ImPACT. Analyses showed BMI provided incremental predictive ability over control variables (i.e. age, gender, sport, number of past concussions) for the visual memory $\left(F(5,317)=2.79, \Delta R^{2}=0.015, p=\right.$ 0.02 ) composite score (table 1$)$. No such prediction emerged for verbal memory $(F(5,317)=$ $\left.3.07, \Delta \mathrm{R}^{2}=0.00, \mathrm{p}=0.260\right)$, visual motor speed $\left(\mathrm{F}(5,317)=1.57, \Delta \mathrm{R}^{2}=0.00, \mathrm{p}=0.31\right)$, reaction time $\left(F(5,317)=0.76, \Delta R^{2}=0.00, p=0.93\right)$, or impulse control $(F(5,317)=0.61$, $\left.\Delta \mathrm{R}^{2}=0.00, \mathrm{p}=0.68\right)$.

In order to further assess the relationship between BMI and cognitive function, partial correlation analyses were conducted between BMI and the five ImPACT composite scores while controlling for number of concussions. For the entire sample, results revealed small but significant negative correlations between BMI and verbal memory $(r=-0.17, p<0.01)$, visual memory, $(r=-0.16, p<0.01)$, and visual motor speed $(r=-0.12, p<0.05)$ (table 2).

Semi-partial correlations were also conducted separately for each gender while controlling for number of concussions. For males, BMI was only significantly associated with visual memory $(r=-0.14, p<0.05)$. For females, BMI was not significantly associated with any composite scores. See tables 3 and 4 for complete correlations for males and females. 
Fedor et al.: Higher BMI Is Associated with Reduced Cognitive Performance in Division I Athletes

Table 1. Linear regressions between BMI and ImPACT composite scores ${ }^{\mathrm{a}}$

\begin{tabular}{lllllll}
\hline & $\mathrm{B}$ & $\mathrm{SE}$ & $\beta$ & $\mathrm{t}$ & $\mathrm{p}$ & $\Delta \mathrm{R}^{2}$ \\
\hline $\begin{array}{l}\text { Verbal memory } \\
\text { Control variables }\end{array}$ & 0.024 & 0.016 & 0.114 & 1.501 & 0.132 & 0.042 \\
$\begin{array}{l}\text { Full model } \\
\text { Visual memory }\end{array}$ & -0.002 & 0.001 & -0.076 & -1.129 & 0.260 & 0.004 \\
$\begin{array}{l}\text { Control variables } \\
\text { Full model }\end{array}$ & 0.012 & 0.022 & 0.042 & 0.551 & 0.582 & 0.027 \\
$\begin{array}{l}\text { Visual motor speed } \\
\text { Control variables }\end{array}$ & -0.004 & 0.002 & -0.152 & -2.240 & 0.026 & 0.015 \\
$\begin{array}{l}\text { Full model } \\
\text { Reaction time }\end{array}$ & 0.186 & 1.287 & 0.011 & 0.145 & 0.885 & 0.021 \\
$\begin{array}{l}\text { Control variables } \\
\text { Full model }\end{array}$ & -0.117 & 0.116 & -0.069 & -1.008 & 0.314 & 0.003 \\
$\begin{array}{l}\text { Impulse control } \\
\text { Control variables }\end{array}$ & -0.005 & 0.014 & -0.029 & -0.381 & 0.704 & 0.012 \\
Full model & 0.000 & 0.001 & 0.006 & 0.085 & 0.933 & 0.000 \\
\hline
\end{tabular}

${ }^{a}$ Control variables included gender, number of past concussions, age, and sport.

Table 2. Correlations between BMI and composite scores for entire sample

\begin{tabular}{|c|c|c|c|c|c|c|}
\hline & BMI & $\begin{array}{l}\text { Verbal } \\
\text { memory }\end{array}$ & $\begin{array}{l}\text { Visual } \\
\text { memory }\end{array}$ & $\begin{array}{l}\text { Visual motor } \\
\text { speed }\end{array}$ & $\begin{array}{l}\text { Reaction } \\
\text { time }\end{array}$ & $\begin{array}{l}\text { Impulse } \\
\text { control }\end{array}$ \\
\hline BMI & - & $-0.17^{* *}$ & $-0.16^{* *}$ & $-0.12^{*}$ & 0.06 & 0.03 \\
\hline Verbal memory & & - & $0.47^{* * *}$ & $0.29 * * *$ & $-0.13^{*}$ & -0.09 \\
\hline Visual memory & & & - & $0.33^{* * *}$ & $-0.17^{* *}$ & $-0.21^{* * *}$ \\
\hline Visual motor speed & & & & - & $-0.32^{* * *}$ & $-0.24 * * *$ \\
\hline Reaction time & & & & & - & $-0.16^{* *}$ \\
\hline Impulse control & & & & & & - \\
\hline
\end{tabular}

*Significant at $\mathrm{p} \leq 0.05$.

$* *$ Significant at $\mathrm{p} \leq 0.01$.

$* * *$ Significant at $\mathrm{p} \leq 0.001$.

Table 3. Correlations between BMI and composite scores for males

\begin{tabular}{|c|c|c|c|c|c|c|}
\hline & BMI & $\begin{array}{l}\text { Verbal } \\
\text { memory }\end{array}$ & $\begin{array}{l}\text { Visual } \\
\text { memory }\end{array}$ & $\begin{array}{l}\text { Visual motor } \\
\text { speed }\end{array}$ & $\begin{array}{l}\text { Reaction } \\
\text { time }\end{array}$ & $\begin{array}{l}\text { Impulse } \\
\text { control }\end{array}$ \\
\hline BMI & - & -0.11 & $-0.14^{*}$ & -0.12 & 0.04 & 0.02 \\
\hline Verbal memory & & - & $0.47^{* * *}$ & $0.30^{* * *}$ & $-9.14^{*}$ & -0.13 \\
\hline Visual memory & & & -- & $0.39 * * *$ & $-0.19^{* *}$ & $-0.29 * * *$ \\
\hline Visual motor speed & & & & - & $-0.36^{* * *}$ & $-0.24^{* * *}$ \\
\hline Reaction time & & & & & - & -0.08 \\
\hline Impulse control & & & & & & - \\
\hline
\end{tabular}

*Significant at $\mathrm{p} \leq 0.05$.

$* *$ Significant at $\mathrm{p} \leq 0.01$.

$* * *$ Significant at $\mathrm{p} \leq 0.001$. 


\begin{tabular}{l|l}
\hline DOI: $10.1159 / 000351138$ & $\begin{array}{l}\text { (c) 2013 S. Karger GmbH, Freiburg } \\
\text { www.karger.com/ofa }\end{array}$ \\
\hline
\end{tabular}

Fedor et al.: Higher BMI Is Associated with Reduced Cognitive Performance in Division I Athletes

Table 4. Correlations between BMI and composite scores for females

\begin{tabular}{|c|c|c|c|c|c|c|}
\hline & BMI & $\begin{array}{l}\text { Verbal } \\
\text { memory }\end{array}$ & $\begin{array}{l}\text { Visual } \\
\text { memory }\end{array}$ & $\begin{array}{l}\text { Visual motor } \\
\text { speed }\end{array}$ & $\begin{array}{l}\text { Reaction } \\
\text { time }\end{array}$ & $\begin{array}{l}\text { Impulse } \\
\text { control }\end{array}$ \\
\hline BMI & - & 0.02 & -0.14 & 0.12 & -0.04 & 0.12 \\
\hline Verbal memory & & - & $0.47^{* * *}$ & $0.22^{*}$ & -0.04 & -0.05 \\
\hline Visual memory & & & - & 0.16 & -0.12 & -0.08 \\
\hline Visual motor speed & & & & - & -0.18 & $-0.25^{*}$ \\
\hline Reaction time & & & & & - & $-0.32^{* * *}$ \\
\hline Impulse control & & & & & & - \\
\hline
\end{tabular}

*Significant at $\mathrm{p} \leq 0.05$.

$* *$ Significant at $\mathrm{p} \leq 0.01$.

$* * *$ Significant at $\mathrm{p} \leq 0.001$

Table 5. Correlations between BMI and composite scores for football players

\begin{tabular}{|c|c|c|c|c|c|c|}
\hline & BMI & $\begin{array}{l}\text { Verbal } \\
\text { memory }\end{array}$ & $\begin{array}{l}\text { Visual } \\
\text { memory }\end{array}$ & $\begin{array}{l}\text { Visual motor } \\
\text { speed }\end{array}$ & $\begin{array}{l}\text { Reaction } \\
\text { time }\end{array}$ & $\begin{array}{l}\text { Impulse } \\
\text { control }\end{array}$ \\
\hline BMI & - & -0.11 & $-0.19 *$ & -0.10 & 0.01 & 0.00 \\
\hline Verbal memory & & - & $0.46^{* * *}$ & $0.33^{* * *}$ & -0.13 & -0.09 \\
\hline Visual memory & & & - & $0.42^{* * *}$ & $-0.17^{*}$ & $-0.27^{* * *}$ \\
\hline Visual motor speed & & & & - & $-0.34^{* * *}$ & $-0.19^{*}$ \\
\hline Reaction time & & & & & - & -0.14 \\
\hline Impulse control & & & & & & - \\
\hline
\end{tabular}

*Significant at $\mathrm{p} \leq 0.05$.

${ }^{* *}$ Significant at $\mathrm{p} \leq 0.01$.

$* * *$ Significant at $\mathrm{p} \leq 0.001$.

\section{BMI and Cognitive Dysfunction in Football Players}

Semi-partial correlations, controlling for number of concussions, were also conducted separately for football players and other sport athletes. The characteristics of the other sports athlete sample has been discussed above. In football players, BMI was only significantly associated with visual memory $(\mathrm{r}=-0.19, \mathrm{p}<0.05)$. For other sport athletes, BMI was not significantly associated with any composite scores. See tables 5 and 6 for complete correlations for football players and other sport athletes.

\section{Discussion}

The findings of the current study indicate that BMI is negatively associated with cognitive function in a sample expected to have better than average cardiovascular fitness. Several features of these findings necessitate further discussion.

BMI was found to be associated with reduced cognitive performance in Division I athletes, but only in specific areas of functioning. Notably, measures of memory had the greatest associations with BMI while no association was found on measures related to executive function and attention. One factor that may be responsible for these differential effects is cardiovas- 
Fedor et al.: Higher BMI Is Associated with Reduced Cognitive Performance in Division I Athletes

Table 6. Correlations between BMI and composite scores for other sport athletes

\begin{tabular}{|c|c|c|c|c|c|c|}
\hline & BMI & $\begin{array}{l}\text { Verbal } \\
\text { memory }\end{array}$ & $\begin{array}{l}\text { Visual } \\
\text { memory }\end{array}$ & $\begin{array}{l}\text { Visual motor } \\
\text { speed }\end{array}$ & $\begin{array}{l}\text { Reaction } \\
\text { time }\end{array}$ & $\begin{array}{l}\text { Impulse } \\
\text { control }\end{array}$ \\
\hline BMI & - & 0.03 & -0.12 & 0.06 & 0.06 & 0.06 \\
\hline Verbal memory & & - & $0.48^{* * *}$ & $0.23^{* *}$ & -0.12 & -0.12 \\
\hline Visual memory & & & - & $0.20 *$ & $-0.18^{*}$ & $-0.16^{*}$ \\
\hline Visual motor speed & & & & - & $-0.27^{* *}$ & $-0.29 * * *$ \\
\hline Reaction time & & & & & - & $-0.20^{*}$ \\
\hline Impulse control & & & & & & - \\
\hline
\end{tabular}

* Significant at $\mathrm{p} \leq 0.05$.

$* *$ Significant at $\mathrm{p} \leq 0.01$.

$* * *$ Significant at $\mathrm{p} \leq 0.001$.

cular fitness. Cardiovascular fitness is known to have a beneficial effect on cognitive functioning [34], including measures of executive function [35] and attention [36]. Such findings raise the possibility that fitness helps to moderate the effects of BMI on some aspects of cognitive function (i.e. memory) but not others (i.e. executive function). Furthermore, no association was found between BMI and ImPACT composite scores for females. The explanation for this pattern is unclear, but may involve the differential risk of concussion in male versus female athletes, underreporting of concussions, or a yet-to-be determined factor. Additional work in other populations is much needed.

The results of the current study indicate that BMI is related to poor cognitive function but the exact mechanisms for this association are unclear. It is possible that athletes with a high BMI who over exert themselves are more likely to exhibit impaired performance on testing. Other possibilities include the known physiological effects of higher BMI, including reduced glycemic control [37] and even reduced perfusion to the frontal brain regions [38]. Future prospective studies are needed to clarify the underlying mechanisms which may be at work, especially studies quantifying physical activity level.

The current study is limited in several ways. An important limitation for the current study involves the manner in which BMI was quantified. BMI is known to be limited in several ways, including poor adjustment for demographic factors (e.g. age, sex), concerns regarding the cut-points for BMI groups, and failure to directly measure body fat [39]. As a result, an individual can be lean with high muscle mass and may still be classified as obese according to BMI. This concern may be particularly relevant in a sample of athletes. However, it is noteworthy that greater BMI was still associated with poorer cognitive function in the current sample, despite these concerns. Future studies should consider alternate measures of obesity, including dual energy X-ray absorptiometry [40]. Another concern involves sample composition as groups were not balanced across gender or sport. The gender imbalance may be particularly important because men and women can be incorrectly identified as obese at different rates [39] and have different incidence rates of concussion [41]. The sport imbalance is also an important consideration as athletes from particular sports may be classified as obese and have very different body types. (i.e., offensive lineman in football vs. a men's basketball player).

In summary, the results of the present study indicate that higher BMI is associated with reduced verbal and visual memory in Division I athletes. Further work is needed to identify the mechanisms by which obesity adversely impacts cognitive function, particularly studies involving neuroimaging. 


\begin{tabular}{l|l|}
\hline Obes Facts 2013;6:185-192 \\
\hline DOI: 10.1159/000351138 & $\begin{array}{l}\text { @ 2013 S. Karger GmbH, Freiburg } \\
\text { www.karger.com/ofa }\end{array}$ \\
\hline
\end{tabular}

Fedor et al.: Higher BMI Is Associated with Reduced Cognitive Performance in Division I Athletes

\section{Disclosure Statement}

The authors have no conflicts of interest to declare.

\section{References}

1 World Health Organization: Obesity and overweight. Published March, 2011. www.who.int/mediacentre/factsheets/fs311/en/index.html (last accessed April 8, 2013).

-2 Mokdad AH, Marks JS, Stroup DF, Gerberding JL: Actual causes of death in the United States, 2000. JAMA 2004; 291:1238-1245. Erratum in JAMA 2005;293:293-294 und JAMA 2005;293:298.

-3 Bray GA: Medical consequences of obesity. J Clin Endocrinol Metab 2004;89:2583-2589.

-4 Centers for Disease Control and Prevention (CDC): Vital signs: state-specific obesity prevalence among adults -- United States, 2009. MMWR Morb Mortal Wkly Rep 2010;59:951-955.

-5 Gustafson D, Rothenberg E, Blennow K, Steen B, Skoog I: An 18 year follow-up of overweight and risk of Alzheimer disease. Arch Intern Med 2003;163:1524-1528.

-6 Fitzpatrick AL, Kuller LH, Lopez OL, Diehr P, O'Meara ES, Longstreth WT Jr, Luchsinger JA: Midlife and late-life obesity and risk of dementia. Arch Neurol 2009;66:336-342.

-7 Gunstad J, Paul RH, Cohen RA, Tate DF, Spitznagel MB, Gordon E: Elevated body mass index is associated with executive dysfunction in otherwise healthy adults. Compr Psychiatry 2007;48:57-61.

-8 Gunstad J, Paul RH, Cohen RA, Tate DF, Gordon E: Obesity is associated with memory deficits in young and middle-aged adults. Eat Weight Disord 2006;11:e15-19.

-9 Hassenstab JJ, Sweat V, Bruehl H, Convit A: Metabolic syndrome is associated with learning and recall impairment in middle age. Dement Geriatr Cogn Disord 2010;29:356-362.

10 Gunstad J, Lhotsky A, Wendell CR, Ferrucci L, Zonderman AB: Longitudinal examination of obesity and cognitive function: Results from the Baltimore longitudinal study of aging. Neuroepidemiology 2010;34:222229.

-11 Huizinga MM, Beech BM, Cavanaugh KL, Elasy TA, Rothman RL: Low numeracy skills are associated with higher BMI. Obesity (Silver Spring) 2008;16:1966-1968.

12 Nilsson LG, Nilsson E: Overweight and cognition. Scand J Psycho 2009;50:660-667.

-13 Fergenbaum JH, Bruce S, Lou W, Hanley AJ, Greenwood C, Young TK: Obesity and lowered cognitive performance in a Canadian First Nations population. Obesity (Silver Spring) 2009;17:1957-1963.

14 Taylor VH, MacQueen GM: Cognitive dysfunction associated with metabolic syndrome. Obes Rev 2007;8:209418.

15 Smith E, Hay P, Campbell L, Troller JN: A review of the association between obesity and cognitive function across the lifespan: implications for novel approaches to prevention and treatment. Obes Rev 2011;12:740755.

16 Sellbom KS, Gunstad J: Cognitive function and decline in obesity. J Alzheimers Dis 2012;30(suppl 2):S89-S95.

-17 Stanek KM, Grieve SM, Brickman AM, Korgaonkar MS, Paul RH, Cohen RA, Gunstad JJ: Obesity is associated with reduced white matter integrity in otherwise healthy adults. Obesity (Silver Spring) 2010;19:500-504.

$\checkmark 18$ Willeumier KC, Taylor DV, Amen DG: Elevated BMI is associated with decreased blow flow in the prefrontal cortex using SPECT imaging in healthy adults. Obesity (Silver Spring) 2011;16:1-3.

19 Gonzales MM, Tarumi T, Miles S, Tanaka H, Shah F, Haley AP: Insulin sensitivity as a mediator of the relationship between BMI and working memory-related brain activation. Obesity (Silver Spring) 2010;18:21312137.

20 de la Monte S M, Tong M, Nguyen V, Setshedi M, Longato L, Wands JR: Ceramide-mediated insulin resistance and impairment of cognitive motor functions. J Alzheimers Dis 2010;21:967-984.

21 Stephan BC, Siervo : Does the improvement in insulin sensitivity mediate the beneficial effects of weight loss on cognitive function? Hypertension 2010;55:1331-1338.

22 Haennel RG, Lemire F: Physical activity to prevent cardiovascular disease. How much is enough? Can Fam Physician 2002;48:65-71.

23 Stunkard A: Physical activity, emotions, and human obesity. Psychosom Med 1958;20:366-372.

- 24 Aberg MA, Pedersen NL, Torén K, Svartengren M, Bäckstrand B, Johnsson T, Cooper-Kuhn CM, Aberg ND, Nilsson M, Kuhn HG: Cardiovascular fitness is associated with cognition in young adulthood. Proc Natl Acad Sci U S A 2009;106:20906-20911.

25 Okonkwo OC, Cohen RA, Gunstad J, Poppas A: Cardiac output, blood pressure, variability, and cognitive decline in geriatric cardiac patients. J Cardiopulm Rehabil Prev. 2011;31:290-297.

26 Hansen AL, Johnsen BH, Sollers JI, Stenvik K, Thayer JF: Heart rate variability and its relation to prefrontal cognitive function: the effects of training and detraining. Eur J Appl Physiol 2004;93:263-272.

-27 Colcombe S, Kramer AF: Fitness effects of the cognitive function of older adults: a meta-analytic study. Psychol Sci 2003;14:125-130.

-28 Smith PJ, Blumenthal JA, Babyak MA, Craighead L, Welsh-Bohmer KA, Browndyke JN, Strauman TA, Sherwood A: Effects of dietary approaches to stop hypertension diet, exercise, and caloric restriction on neurocognition in overweight adults with high blood pressure. Hypertension 2010;55:1331-1338. 
Fedor et al.: Higher BMI Is Associated with Reduced Cognitive Performance in Division I Athletes

-29 Wilkerson GB, Bullard JT, Bartal DW: Identification of cardiometabolic risk among collegiate football players. J Athl Train 2010;45:67-74.

30 Lovell M: ImPACT Version 6.0 Clinical Interpretation Manual. Published 2007. www.impacttest.com/pdf/ ImPACT_Clinical_Interpretation_Manual.pdf (last accessed April 8, 2013).

31 Iverson GL, Franzen MD, Lovell MR, Collins MW: Construct validity of computerized neuropsychological screening in athletes with concussion. Arch Clin Neuropsychol 2004;19:961-962.

-32 Schatz P, Pardini JE, Lovell MR, Collins MW, Podell K: Sensitivity and specificity of the ImPACT test battery for concussion in athletes. Arch Clin Neuropsychol 2006;21:91-99.

33 SPSS Version 16: IBM Corporation, Somers, NY, USA, 2008.

-34 Colcome S, Kramer AF, Erickson KI, Scalf P, McAuley E, Cohen NJ, Webb W, Jerome GJ, Marquez DX, Elavsky S: Cardiovascular fitness, cortical plasticity, and aging. Proc Natl Acad Sci U S A 2004;101:3316-3321.

35 Kakos LS, Szabo AJ, Gunstad J, Stanek KM, Waechter D, Hughes J, Luyster F, Josephson R, Rosneck J: Reduced executive functioning is associated with poorer outcome in cardiac rehabilitation. Prev Cardiol 2010;13:100103.

36 Stevenson JS, Topp R: Effects of moderate and low intensity long-term exercise by older adults. Res Nurs Health 1990;13:209-218.

-37 Cukierman-Yaffe T, Sulivan MD, Gerstein HC, Marcovina SM, Williamson JD, Launer LJ, Lazar RM, Lovato L, Miller MC, Coker LH, Murray A: Relationship between baseline glycemic control and cognitive function in individuals with type 2 diabetes and other cardiovascular risk factors. Diabetes Care 2009;32:221-226.

38 Willeumier KC, Taylor DV, Amen DG: Elevated BMI is associated with decreased blood flow in the prefrontal cortex using SPECT imaging in health adults. Obesity (Silver Spring) 2011;19:1095-1097.

39 Rothman KJ: BMI-related errors in the measurement of obesity. Int J Obes 2008;32:56-59.

40 Kohrt WM: Abdominal obesity and associated cardiovascular comorbidities in the elderly. Coron Artery Dis 1998;9:489-494.

41 Covassin T, Swanik CB, Sachs ML: Sex differences and the incidence of concussions among collegiate athletes. J Athl Train 2003;38:238-244. 